\title{
Conhecimentos e condutas sobre saúde bucal dos docentes de Ensino Fundamental
}

\section{de um município de Alagoas}

\author{
Knowledge and conduct on oral health of Elementary School teacher in a municipality of Alagoas \\ Conocimientos y conducta sobre salud bucal de docentes de Escuelas Primarias en un municipio de
}

Alagoas

Paulla Valéria de Souza Meneses

ORCID: https://orcid.org/0000-0001-6749-9377

Universidade Estadual de Ciências da Saúde de Alagoas, Brasil

E-mail: paullavaleria@hotmail.com

Érica Paula Barbosa

ORCID: https://orcid.org/0000-0002-8280-4699

Universidade Estadual de Ciências da Saúde de Alagoas, Brasil

E-mail: erica.barbosa@ academico.uncisal.edu.br

Cinthya Rafaella Magalhães da Nóbrega Novaes

ORCID: https://orcid.org/0000-0003-4795-6328

Universidade Estadual de Ciências da Saúde de Alagoas, Brasil

E-mail: rafamn20@yahoo.com.br

Ana Renata Lima Leandro

ORCID: https://orcid.org/0000-0003-2707-0730

Universidade Estadual de Ciências da Saúde de Alagoas, Brasil E-mail: releandro@gmail.com

Adhemar Ranciaro Neto

ORCID: https://orcid.org/0000-0003-3360-9843 Universidade Federal de Alagoas, Brasil E-mail: adhrneto@hotmail.com

Flávia Accioly Canuto Wanderley ORCID: https://orcid.org/0000-0003-0775-9119 Universidade Estadual de Ciências da Saúde de Alagoas, Brasil E-mail: flavia.accioly@uncisal.edu.br

Carmen Silvia Motta Bandini

ORCID: https://orcid.org/0000-0002-4731-5785

Universidade Estadual de Ciências da Saúde de Alagoas, Brasil E-mail: carmen.bandini@uncisal.edu.br

\begin{abstract}
Resumo
O presente estudo teve como objetivo avaliar os conhecimentos sobre saúde bucal dos docentes do ensino fundamental das escolas públicas de um município de Alagoas e identificar as condutas adotadas pelos professores frente aos problemas bucais mais frequentes. Para isso, realizou-se um estudo descritivo, com abordagem quantitativa, junto a 77 docentes, por meio de um questionário eletrônico organizado em duas partes: a primeira, sobre aspectos sociodemográficos e práticas pedagógicas de saúde bucal e a segunda, com questões específicas sobre os conhecimentos básicos de saúde bucal e as condutas que os professores tomariam frente aos problemas odontológicos mais frequentes. Os professores tiveram um prazo de duas semanas para a devolutiva do questionário. Com relação à saúde bucal, verificou-se que $88,3 \%$ dos professores afirmaram conhecimento sobre cárie, 96,1\% como evitá-la e $71,4 \%$ expuseram que sabiam como escovar os dentes dos alunos. Sobre condutas e atitudes, constatou-se que $62,3 \%$ dos professores não levavam os alunos para escovar os dentes; 62,3\% não sabiam o que fazer frente a um acidente que atingisse a boca do aluno e $94,8 \%$ não manteriam o aluno em sala de aula diante da queixa específica de dor de dente. Pelos dados analisados, conclui-se que os conhecimentos e as condutas apresentadas pelos professores foram considerados insatisfatórios e, muitas vezes, superficiais, pois partiram, predominantemente da prática diária (conhecimento empírico) e não estiveram permeados, na maior parte das vezes, por informações técnicas suficientes. Palavras-chave: Educação em saúde bucal; Conhecimentos, atitudes e práticas em saúde; Docentes; Ensino.
\end{abstract}

\footnotetext{
Abstract

The present study aimed to assess the knowledge about oral health of teachers in public elementary schools in a municipality in Alagoas and to identify the behaviors adopted by teachers in face of the most frequent oral problems.
} 
For this, a descriptive study was carried out, with a quantitative approach, with 77 professors, through an electronic questionnaire organized in two parts: the first, on sociodemographic aspects and pedagogical practices of oral health, and the second, with specific questions about the basic knowledge of oral health and the behavior that teachers would take in face of the most frequent dental problems. Teachers had a period of two weeks to return the questionnaire. With regard to oral health, it was found that $88.3 \%$ of teachers said they knew about caries, $96.1 \%$ how to avoid it and $71.4 \%$ said they knew how to brush students' teeth. Regarding behavior and attitudes, it was found that $62.3 \%$ of teachers did not take students to brush their teeth; $62.3 \%$ did not know what to do in the face of an accident that affected the student's mouth and $94.8 \%$ would not keep the student in the classroom due to the specific complaint of toothache. From the analyzed data, it is concluded that the knowledge and behavior presented by the teachers were considered unsatisfactory and often superficial, as they started predominantly from daily practice (empirical knowledge) and were not permeated, in most cases, by information enough techniques.

Keywords: Oral health education; Health knowledge, attitudes and practices; Teachers; Teaching.

\section{Resumen}

El presente estudio tuvo como objetivo evaluar los conocimientos sobre salud bucal de docentes de educación primaria en escuelas públicas de una ciudad de Alagoas e identificar las conductas adoptadas por los docentes ante los problemas bucales más frecuentes. Para ello, se realizó un estudio descriptivo, con enfoque cuantitativo, con 77 profesores, a través de un cuestionario electrónico organizado en dos partes: la primera, sobre aspectos sociodemográficos y prácticas pedagógicas de la salud bucal, y la segunda, con preguntas específicas sobre el Conocimientos básicos de salud bucal y el comportamiento que el profesorado tomaría ante los problemas dentales más frecuentes. Los profesores disponían de un plazo de dos semanas para devolver el cuestionario. Con respecto a la salud bucal, se encontró que el 88,3\% de los docentes dijo conocer la caries, el 96,1\% cómo evitarla y el 71,4\% dijo saber cómo cepillar los dientes de los estudiantes. En cuanto a comportamientos y actitudes, se encontró que el 62,3\% de los docentes no llevaban a los alumnos a cepillarse los dientes; El 62,3\% no sabía qué hacer ante un accidente que afectó la boca del alumno y el 94,8\% no mantendría al alumno en el aula ante una queja concreta de dolor de muelas. De los datos analizados se concluye que los conocimientos y comportamientos presentados por los docentes fueron considerados insatisfactorios y muchas veces superficiales, ya que partían predominantemente de la práctica diaria (conocimientos empíricos) y no estaban permeados, en la mayoría de los casos, por técnicas de suficiente información.

Palabras clave: Educación en salud bucal; Conocimientos, actitudes y prácticas en salud; Maestros; Enseñando.

\section{Introduçãa}

A saúde bucal é parte integrante e fundamental da saúde em geral, e mudanças para melhorias nas condições de saúde bucal, atualmente, estão voltadas para a área da educação, investindo na motivação de alunos e professores para que eles compreendam a importância de se educar para a saúde, a fim de efetivar a prevenção como questão principal de saúde coletiva (Carvalho et al., 2017).

A cárie é o agravo que acomete a cavidade oral com maior frequência (Lemkuhl et al., 2015) e o Brasil é o país que apresenta um dos maiores índices dessa doença (Sá \& Vasconcelos, 2009). Ela é considerada um problema de saúde pública, devido à dor e ao sofrimento causados e o impacto gerado na qualidade de vida dos indivíduos. (Vazzoler \& Cericato, 2016).

Além de causar danos individuais, como o comprometimento da capacidade funcional, a cárie ainda acarreta ônus para o sistema de saúde (Campos et al., 2008) e verifica-se que ela acontece de forma díspar na população, atingindo, em maior número, crianças e adolescentes de famílias de classes sociais menos favorecidas e com menor grau de escolaridade (Silva et al., 2013).

A cárie é prevenida com uso de procedimentos de baixo custo e de fácil execução, como a correta escovação dos dentes e o uso do fio dental, para um efetivo controle do biofilme dental, seu principal fator etiológico (Alves et al., 2003; Santos et al., 2019). No entanto, esse controle requer cooperação do paciente (Campos et al., 2008).

A prática desses procedimentos demanda reforço e repetição contínua. Nesse sentido, a escola é um ambiente propício para o ensino desses procedimentos. O professor, por seu contato diário com as crianças, torna-se um importante aliado para ajudá-las a perceber a real necessidade de se escovar os dentes e de usar o fio dental. O professor pode, também, trazer para 
sala de aula conhecimento sobre como as doenças bucais acontecem, seu curso natural e qual a melhor forma de prevenção (Sá \& Vasconcelos, 2009; Garbin et al., 2012; Garbin et al., 2013).

Essas práticas educativas em saúde e a introdução do conteúdo acerca da saúde bucal no currículo do ensino infantil, fundamental e médio, viabilizariam formar crianças e adolescentes com perfil diferenciado, aptos a aplicarem os conhecimentos adquiridos de forma mais profunda dentro do contexto de cada faixa etária e a realizar sua própria promoção de saúde bucal (Cordeiro et al., 2019).

Apesar de esses procedimentos serem de fácil execução, baixo custo e possíveis de serem realizados na escola, o nível de conhecimento dos professores sobre o tema tem sido considerado baixo, com deficiência no entendimento de determinados assuntos. Embora desenvolvam práticas educativas sobre saúde bucal, os professores não estão preparados para abordar conteúdos de saúde bucal com segurança em sala de aula e são necessários mais esclarecimentos para que eles possam orientar os alunos de maneira adequada (Pinheiro et al., 2005; Granville Garcia et al., 2007; Garbin et al., 2013).

Antunes, Soraggi, Antunes e Corvino (2006) apontam que a falta de entendimento sobre os conhecimentos, as atitudes e as práticas de saúde bucal desempenhadas por educadores levam a implantação, muitas vezes, inadequada de políticas de saúde que não alcançam os resultados esperados e, em muitos casos, a impossibilidade de se saber se campanhas educativas podem trazer algum benefício para determinada comunidade. Nesse sentido, o nível de conhecimento a respeito de saúde bucal é um dado de extrema importância para o planejamento e avaliação das ações em saúde bucal, buscando-se estratégias a partir dos dados coletados.

Sendo assim, é preciso que ações nas escolas tenham como ponto de partida uma avaliação sobre o conhecimento dos professores sobre saúde bucal, se essa temática é trabalhada em sala de aula e, em casos positivos, de que maneira isso é feito principalmente considerando o seu papel na formação dos cidadãos (Rebello et al., 2018).

Dado o exposto, o presente estudo se propôs a avaliar os conhecimentos sobre saúde bucal dos docentes do Ensino Fundamental das Escolas Públicas Municipais de um município de Alagoas, bem como identificar as condutas adotadas pelos professores frente aos problemas bucais mais frequentes.

\section{Metodologia}

Foi realizado um estudo descritivo, com abordagem quantitativa (Toassi \& Petry, 2021). Os sujeitos da pesquisa foram os docentes das Escolas de Ensino Fundamental de um município de Alagoas. A amostra foi não aleatória, por conveniência, composta pelos professores de $1^{\circ}$ e $2^{\circ}$ anos das Escolas Municipais de Ensino Fundamental. Do total de 200 professores existentes e convidados, 77 (38,5\%) responderam à pesquisa, que foi aprovada pelo Comitê de Ética em Pesquisa (CEP) da Universidade Estadual de Ciências da Saúde de Alagoas (UNCISAL), por meio do parecer n 4.470.614, CAAE 40021020.1.0000.5011.

Inicialmente, fez-se contato com a Secretária Municipal de Educação e foram apresentados os objetivos, a metodologia, a justificativa do estudo e prestados esclarecimentos sobre a confidencialidade das informações. Na ocasião, foi assinado o Termo de Anuência da Secretaria Municipal de Educação concordando com o estudo.

Após a assinatura desse documento de autorização para a realização da pesquisa e a aprovação pelo CEP, foi realizada uma reunião com os professores, durante a I Semana Pedagógica Municipal. E para a exposição dos objetivos e procedimentos da pesquisa e esclarecimentos, quanto à participação voluntária de cada um, utilizou-se uma plataforma virtual, gratuita.

Após esse momento inicial, foi disponibilizado para os professores, por meio dos diretores das instituições das quais pertencem, um questionário eletrônico desenvolvido por Pinheiro et al. (2005) e Campos et al. (2008) sem qualquer atividade educativa prévia. Nele, foram passadas apenas orientações sobre o seu correto preenchimento, por meio de um link direto 
provido por um software colaborativo de gerenciamento de pesquisas na internet, de domínio público e gratuito, o Google forms. O acesso deu-se tanto por meio da web, como de sistemas operacionais de Android e iOS. O tempo estimado para responder o questionário eletrônico foi calculado, em média, de 10 minutos e foi estipulado o prazo de 2 semanas para a devolutiva do formulário.

O questionário eletrônico era semiestruturado, autoexplicativo e contava com 30 perguntas incluindo questões abertas e fechadas. As perguntas fechadas eram do tipo dicotômicas (sim ou não) e com opção pré-determinadas (múltipla escolha), com uma adaptação, solicitada pelo CEP, incluindo a opção "não desejo responder" a todas as perguntas do instrumento.

$\mathrm{O}$ instrumento foi organizado em duas partes: a primeira, com 6 perguntas do questionário validado por Campos et al. (2008), que correspondem a aspectos sociodemográficos e práticas pedagógicas de saúde bucal: gênero, tempo de atuação profissional, faixa etária, grau de escolaridade, participação em aperfeiçoamento e atividades realizadas em sala de aula sobre saúde bucal, e a segunda, com 24 questões específicas sobre os conhecimentos básicos de saúde bucal e sobre as condutas que os professores adotariam frente aos problemas odontológicos mais frequentes validadas por Pinheiro et al. (2005).

Após encerramento do prazo estipulado para devolutiva das respostas, todos os dados obtidos com o questionário foram tabulados, transferidos para planilha Excel e os professores identificados por números. Em seguida, foi utilizado o software R Core Team 2020 para os cálculos e os dados foram submetidos à análise descritiva, por meio de distribuição de frequência absoluta (n) e relativa (\%).

\section{Resultados e Discussão}

O questionário online foi disponibilizado para 200 professores de $1^{\circ}$ e $2^{\circ}$ ano do Ensino Fundamental, do total, 80 (40\%) abriram o formulário enviado, porém 3 não aceitaram participar da pesquisa, declinando assinar o TCLE. Dessa forma, a amostra final foi composta por 77 professores que aceitaram participar da pesquisa e que responderam às perguntas. Dos participantes da pesquisa, 57\% informaram lecionar no $1^{\circ}$ ano do Ensino Fundamental e $43 \%$, no $2^{\circ}$ ano.

Analisados os dados da pesquisa, pode-se constatar que houve a predominância do gênero feminino (93,5\%), essa característica da amostra assemelha-se aos estudos de Campos et al. (2008), Vellozo, Queluz, Mialhe e Pereira (2008) e Rebello et al. (2018), que obtiveram uma maioria dos sujeitos do gênero feminino, 97\%, 93,2\% e 82,6\%, respectivamente. Esses estudos tinham o objetivo analisar o nível de conhecimento e práticas em saúde bucal de professores.

As faixas etárias de 30-39 (23,3\%) e 40-49 anos (54,5\%) foram as mais predominantes. Embora o predomínio seja de jovens professores, eles não têm informações sobre saúde bucal, mesmo com a facilidade para aquisição dessas informações por meios eletrônicos, por exemplo. Com relação à escolaridade, observou-se que a maioria (74\%) cursou até o nível da especialização lato sensu. No entanto, os conhecimentos sobre saúde bucal por eles apresentados na presente pesquisa, por vezes, foram superficiais e permeados pelo senso comum.

Outra variável analisada, relativa ao perfil dos professores, foi o tempo de atuação, agrupado em intervalos de cinco anos. Verificou-se que 36,3\% da amostra declarou lecionar entre 5 e 10 anos, seguido por 23,3\% que já atuam entre 21 e 25 anos. Verifica-se, portanto, que o tempo de atuação da presente amostra é menor que o descrito por Campos et al. (2008), que reportaram uma frequência de 54\% de professores com mais de 7 anos de atuação e por Granville Garcia et al. (2007), que apontam 66,8\% com mais de 6 anos de experiência profissional. Por fim, a amostra de Santos, Casotti, Guimarães e Queiroz, Carneiro e Uemura (2015) contou com um percentual de 92,8\% de professores com mais de 10 anos de atuação. Apesar de muitos professores envolvidos na amostra da presente pesquisa possuírem tempo de atuação inferior ou igual a 10 anos, destaca-se o fato de que 23,3\% da amostra informou ter tempo de atuação entre 21 e 25 anos. Dessa forma, são considerados professores experientes por lecionarem no período em várias turmas diferentes e por mais de duas décadas. Nesse contexto, 
esperava-se que pudessem apresentar conhecimentos mais sólidos sobre o assunto, advindos de capacitações e formações recorrentes, o que não foi verificado quando questionados sobre condutas adequadas para a saúde bucal dos alunos, como se verá nos resultados advindos das perguntas específicas sobre o tema.

Dos 77 professores que responderam ao questionário, 75,3\% participaram de capacitação nos últimos dois anos, mas apenas $5,1 \%$ deles receberam informações sobre saúde bucal nesses momentos. Dados semelhantes foram encontrados por Campos et al. (2008), que apontam que $80 \%$ dos professores já haviam participado de algum tipo de capacitação nos últimos dois anos, mas, a maioria não havia recebido informação sobre saúde bucal. Esses dados são também corroborados pelos achados da pesquisa de Santos et al. (2015), na qual mais da metade dos professores $(57,4 \%)$ afirmou ter participado de algum curso de capacitação nos últimos dois anos, mas apenas 7,4\% receberam orientação sobre saúde bucal, o que correspondeu a apenas 1 (um) indivíduo. Os resultados da presente pesquisa e os dados encontrados na literatura apontam para o fato de que nas capacitações das quais os professores têm participado, o tema saúde bucal não é abordado com frequência, sendo assim, supõe-se que os conhecimentos apresentados pelos professores tenham origem em informações adquiridas fora da formação acadêmica desses docentes.

Nas respostas apresentadas pelos professores participantes desse estudo, 88,3\% afirmaram saber o que é a cárie, 7,7\% optaram por não responder e 3,9\% expuseram não possuir nenhum tipo de informação sobre como a cárie ocorre. Pinheiro et al. (2005) encontraram dados semelhantes, em que $86 \%$ dos professores afirmaram ter conhecimento sobre o assunto. Silva (2015) observou que $97 \%$ dos professores participantes do seu estudo receberam informações sobre saúde bucal em algum momento da vida, incluindo a cárie. Já Cordeiro et al., (2019) trazem que apenas 39,5\% dos docentes afirmaram ter recebido informações sobre saúde bucal durante a graduação, consequentemente, sobre a cárie. Para que os professores possam melhor discutir sobre saúde bucal, faz-se necessário que sejam capacitados para tal abordagem em sala de aula, para tanto, pode-se incluir a temática na graduação e capacitações desses profissionais, pois para que eles possam atuar como promotores de saúde na escola, é importante que estejam capacitados. A Figura 1 mostra as respostas dadas pelos professores sobre a etiologia da cárie.

Figura 1 - Número de respostas que professores de $1^{\circ}$ e $2^{\circ}$ ano de Escolas Municipais de Ensino de um município de Alagoas deram sobre a etiologia da cárie.

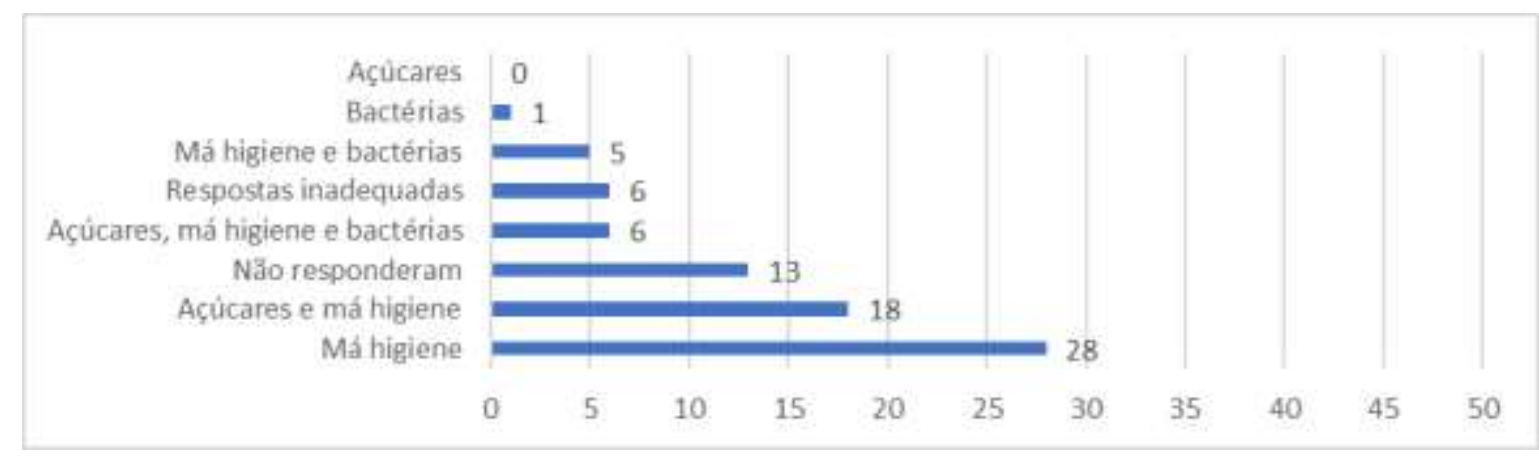

Fonte: Autores (2021).

Quando questionados sobre a etiologia da cárie, os professores do presente estudo destacaram a má higiene oral isoladamente $(36,3 \%)$ como principal causa da cárie, seguida dela associada ao fator açúcar $(23,3 \%)$ e apenas $8,1 \%$ colocaram a multifatorialidade como responsável por seu surgimento. Tal fato reflete pouco conhecimento dos participantes neste aspecto e isso pode ser atribuído, segundo Campos et al. (2008), a falta dessas informações durante a formação e capacitação dos professores, dado que a cárie dentária tem sido definida como uma doença multifatorial resultante de um processo dinâmico de 
eventos metabólicos que ocorrem pela interação entre dieta, suscetibilidade do dente, presença de microrganismos e tempo. (Aboped, 2020). Apesar dos achados acompanharem parte da literatura, Costa, Barbosa, Fernandes, Fonseca e Paredes (2014) encontraram resultados divergentes dos oriundos dessa pesquisa, uma vez que os professores destacaram a multifatorialidade (74,5\%), seguida do binômio açúcares e má higiene (16\%) e só depois a má higiene oral isoladamente foi citada (11,8\%) como causas da cárie. Nesse sentido, verifica-se que é possível formar professores de modo a transformá-los em aliados para a conduta adequada de seus alunos, frente ao cuidado com a saúde bucal.

Um dado que chama a atenção é o de que, na presente pesquisa, seis professores $(7,7 \%)$, ao serem questionados sobre a etiologia da cárie, deram respostas não relacionadas ao assunto, como por exemplo, forneceram informações sobre como aprenderam sobre o tema (relataram receber informações por meio de panfletos, internet, através do dentista e/ou de vídeos) ou relataram que possuíam noções básicas iniciais, mas não descreveram quais seriam essas informações. Estas respostas foram agrupadas na categoria "respostas inadequadas" (Figura 1), isto pode ser um dado resultante de má interpretação da pergunta ou mesmo do cansaço ao responder ao questionário eletrônico.

Costa et al. (2014) e Granville Garcia et al. (2007) mencionam que os professores apontam a cárie como doença, com um percentual de 54,3\% e 36,7\%, respectivamente. Concordando com os achados descritos acima, Garbin et al. (2013) encontraram que $38 \%$ dos professores de seu estudo acreditam que a cárie é uma patologia, porém, que independe da presença de microrganismos, e que as disciplinas de Ciências e Biologia são as principais responsáveis por promoverem saúde e reforçar bons hábitos. No entanto, nenhuma resposta dos participantes da pesquisa ora apresentada colocou a cárie como uma doença quando foram questionados, em pergunta aberta, sobre quais as informações possuíam sobre como a cárie ocorre.

Em outra questão, perguntou-se aos professores se eles sabiam como evitar a cárie e 96,1\% afirmaram saber, contra apenas 1,3\% que alegaram não ter essas informações e 2,6\% professores que optaram por não responder à questão. As informações apresentadas pelos professores sobre como evitar a cárie estão expostas na Figura 2.

Figura 2 - Frequência absoluta (N) das informações que os professores de $1^{\circ}$ e $2^{\circ}$ ano de Escolas Municipais de Ensino de um município de Alagoas possuem sobre como evitar a cárie.

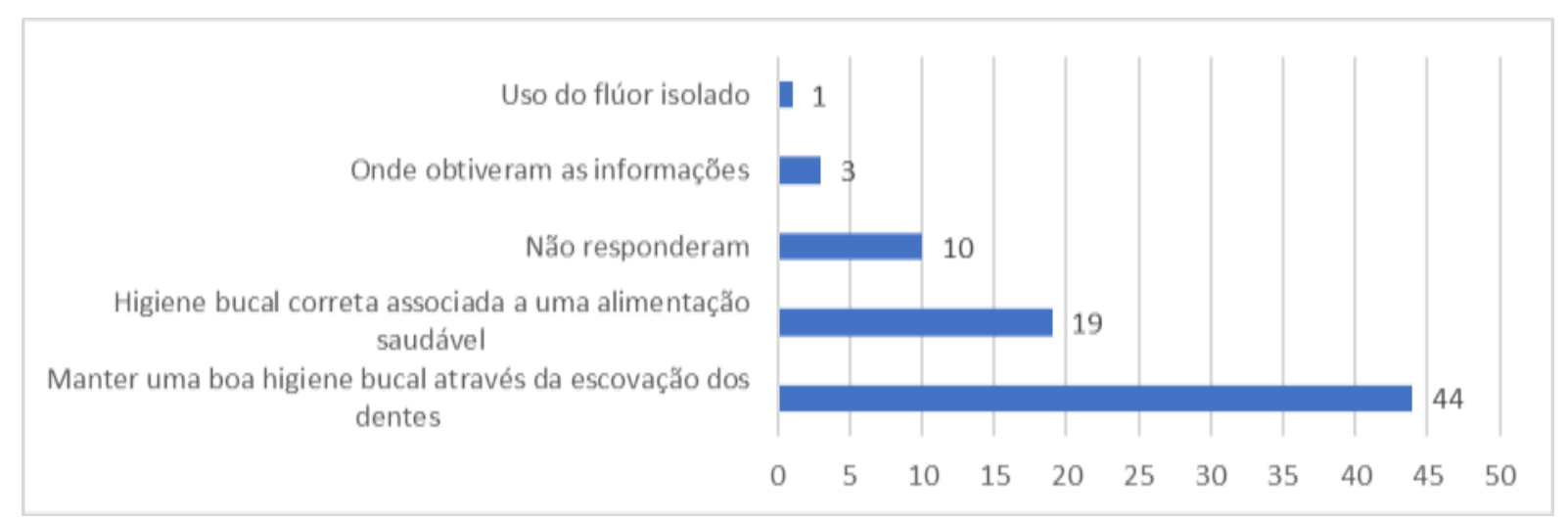

Fonte: Autores (2021).

Pouco mais da metade dos professores $(57,1 \%)$ acredita que a cárie pode ser evitada através da escovação dos dentes e 24,7\% associaram a prevenção das cáries a hábitos de higiene bucal corretos e alimentação saudável. Já 12,9\% dos professores não apresentaram nenhum tipo de resposta, ao passo que, houve respostas não relacionadas a prevenção das cáries, 3,8\%, por exemplo, informaram onde obtiveram os conhecimentos (panfletos, vídeos, com o dentista e através de leitura sobre o assunto) e um único professor associou a prevenção da cárie ao uso isolado do flúor. Os dados de não resposta e de respostas que não se 
relacionam a pergunta feita, novamente chamam a atenção para a possibilidade de má interpretação da pergunta realizada ou para o cansaço dos professores ao responderem ao questionário.

No que tange às informações sobre o flúor, observou-se que os professores têm menos informações sobre essa temática em relação à cárie dentária, uma vez que 64,9\% disseram já ter recebido informações sobre flúor, 28,5\% dos professores afirmaram não ter informações sobre o flúor e 6,4\% não quiseram responder à questão. Esse fato fica mais evidente quando foi solicitado aos professores que apresentassem quais eram as informações que tinham a respeito do flúor e pouco mais da metade $(n=39,50,6 \%)$ não teceu nenhum tipo de comentário. Talvez esse fato tenha ocorrido pela não compreensão da pergunta formulada, ou dificuldade de se expressar sobre o tema. As informações descritas pelos professores nessa questão versavam sobre a importância e função do flúor, como deve ser aplicado, locais onde pode ser encontrado, e o responsável pela aplicação.

Arcieri et al. (2013) apontaram que 88,4\% dos professores do seu estudo indicaram conhecer sobre flúor, destes $50,3 \%$ atribuíram ao mesmo a função de proteção da estrutura dental, $22 \%$ a prevenção contra cárie e $18 \%$ ao fortalecimento da estrutura dental. No entanto, para Garbin et al. (2013), 78,1\% dos professores da sua amostra não descreveram corretamente a função do flúor. No presente estudo, $22 \%$ das respostas também foram respondidas de forma equivocada, conforme citado acima. Foram encontradas respostas como: reforço na limpeza dos dentes, usado à noite antes de dormir e fonte da informação (internet, panfletos etc.). Em contrapartida, no estudo de Santos, Rodrigues e Garcia, (2003) 98,2\% dos professores souberam responder sobre a função do flúor e, 36,9\% deles a associam seu uso ao fortalecimento do esmalte e 70,3\% à prevenção da cárie.

Sobre a realização de alguma atividade sobre saúde bucal com os alunos, 84,4\% dos professores declararam realizar tais atividades, 11,6\% não realizam e 3,9\% não forneceram resposta a essa questão. Nos estudos de Arcieri et al. (2013) e Campos et al. (2008), todos os professores acreditam ser importante a realização de atividades sobre saúde bucal e afirmaram tratar desse assunto em sala de aula, número expressivamente maior do que o encontrado por Pinheiro et al. (2005), em que $71 \%$ dos professores pesquisados relataram não realizar tais atividades.

A temática atividades em sala de aula sobre saúde bucal foi abordada em duas oportunidades no instrumento da presente pesquisa, na questão seis (realiza alguma atividade em sala de aula em relação à saúde bucal), com alternativas de múltipla escolha e na questão nove (você já realizou alguma atividade relacionada ao conhecimento da saúde bucal dos seus alunos) questão aberta, para ambas as frequências de respostas estão expostas nas Figuras 3 e 4 a seguir.

Figura 3 - Frequência absoluta $(\mathrm{N})$ das respostas dos professores de $1^{\circ}$ e $2^{\circ}$ anos acerca das atividades desenvolvidas em sala de aula sobre saúde bucal nas Escolas Municipais de Ensino de um município de Alagoas (questão 6).

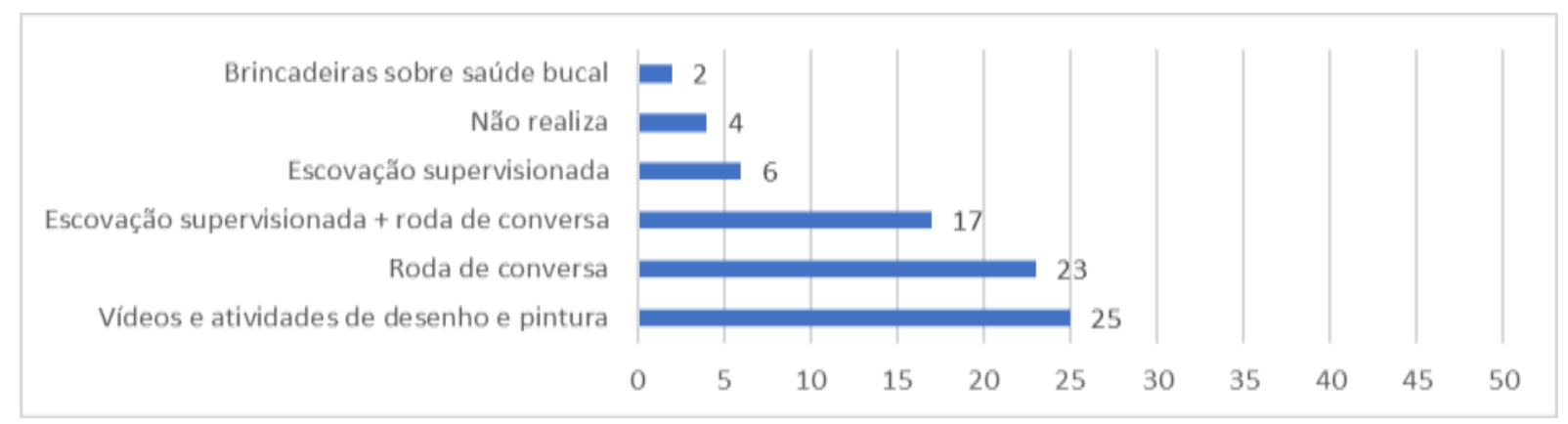

Fonte: Autores (2021). 
Figura 4 - Número de respostas de atividades sobre saúde bucal já realizadas em sala de aula pelos professores de $1^{\circ}$ e $2^{\circ}$ ano de Escolas Municipais de Ensino de um município de Alagoas (questão 9).

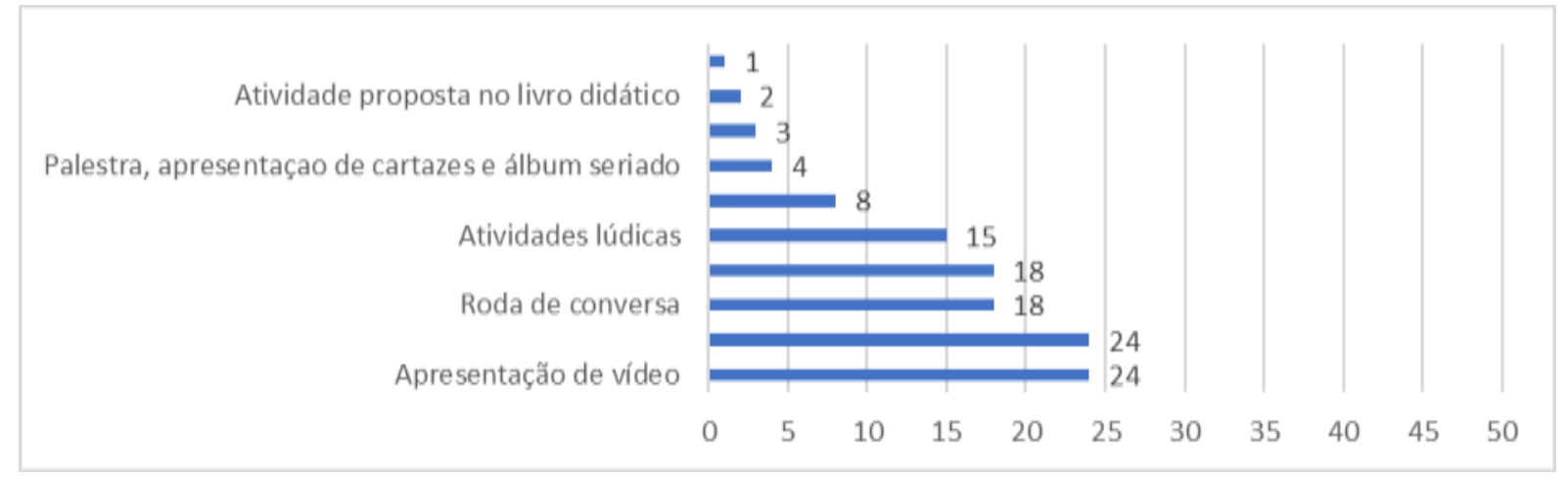

Nota: nessa questão houve a possibilidade de serem fornecidas mais de uma resposta. Fonte: Autores (2021).

Foi observado que as respostas dadas pelos professores, em ambas as questões, estiveram em sintonia. Eles destacaram como atividades sobre saúde bucal: a apresentação de vídeos, a demonstração de escovação e a roda de conversa. No entanto, na questão aberta, houve uma maior diversidade de respostas, contribuindo para expressão do professor, respostas estas que não foram contempladas na questão de múltipla escolha, como por exemplo, apresentação de cartazes, álbum seriado, leitura, entre outras.

No que diz respeito à escovação dos dentes dos alunos, foi questionado se os professores possuíam alguma informação. Dos respondentes, 71,4\% alegaram saber como realizar a escovação, 18\% argumentaram não ter essas informações e 10,3\% preferiram não responder. Na questão seguinte perguntou-se em que horário os professores levavam os alunos para escovar os dentes e mais da metade, ou seja, 62,3\%, alegaram não levar os alunos para escoar os dentes. Para uma melhor compreensão desses resultados precisa-se considerar alguns fatores: 1) a escova está disponível na escola para realizar a escovação? 2) há um local adequado para que a escovação seja feita? E, por fim, 3) o professor está apto a realizar essa atividade? No município em que a pesquisa foi realizada, a escovação ainda não é rotina em muitas de suas Instituições de Ensino e não existe regulamentação para que a escovação seja realizada pelo professor. Assim, tal ação de prevenção deixa de ser executada nas escolas, dada a falta de rotina escolar ou de estrutura (local apropriado, disponibilização das escovas e demais material de higiene bucal).

No estudo de Pinheiro et al. (2005), metade dos professores afirmaram ter informações sobre a escovação de dentes dos alunos, no entanto, os autores classificaram o nível de conhecimento dos professores sobre saúde bucal como baixo e julgam necessários mais esclarecimentos sobre o tema, para que possam orientar os alunos, uma vez que 88,2\% informaram orientar as escovações das crianças ainda que não possuam conhecimento de como realizá-la. Fato este constatado também pelo presente estudo, em que 70,1\% dos professores disseram orientar os alunos de acordo com o conhecimento que possuíam sobre o assunto. Esse resultado pode ser atribuído ao fato, como já citado por Campos et al. (2008), de que os professores não receberem orientações específicas de saúde bucal em sua graduação e formação continuada. Dentre as respostas observadas, apenas 1 professor $(1,2 \%)$ disse não orientar os alunos por não possuir informações necessárias para esclarecê-los. Os demais professores disseram dar importância a dúvida dos alunos, porém 70,1\% deles procurariam responder de acordo com o conhecimento que possuíam, 15,5\% procurariam alguém que pudesse esclarecer a dúvida para depois repassar a informação correta aos alunos e 12,9\% orientariam a seu modo pois, informaram não ter conhecimentos específicos sobre o assunto.

Diante da queixa específica de dor de dente pelo aluno, as condutas adotadas pelos professores estão descritas, a seguir, na Tabela 1. 
Tabela 1 - Frequência absoluta $(\mathrm{N})$ e relativa $(\%)$ de quais atitude os professores de $1^{\circ}$ e $2^{\circ}$ ano de Escolas Municipais de Ensino de um município de Alagoas teriam diante da queixa de dor de dente pelo aluno.

\begin{tabular}{|c|c|c|}
\hline & $\mathrm{N}$ & $\%$ \\
\hline Mandaria o aluno para casa, mas orientando os pais a procurar um tratamento para seu filho & 61 & 79,22 \\
\hline Procuraria encaminhar o aluno a um posto de saúde ou a um outro local que tivesse um dentista para atendê-lo & 12 & 15,59 \\
\hline Procuraria um remédio na escola para aliviar a sua dor & 3 & 3,9 \\
\hline $\begin{array}{l}\text { Não faria nada e continuaria com as suas atividades normais, só comunicando aos pais da situação quando estes } \\
\text { fossem buscar o aluno na escola }\end{array}$ & 1 & 1,29 \\
\hline Mandaria o aluno para casa, sem orientar aos pais a procurar um tratamento para o seu filho & 0 & 0 \\
\hline Não desejo responder & 0 & 0 \\
\hline
\end{tabular}

Fonte: Autores (2021).

Observa-se que 94,8\% dos professores não manteriam o aluno na escola, seja mandando-o para casa, e por sua vez, orientando os pais a procurarem atendimento; $(79,2 \%)$, encaminhando por iniciativa própria, a um posto de saúde ou outro local para atendimento (15,5\%). Já na pesquisa de Pinheiro et al. (2005), 50\% dos professores encaminhariam o aluno para casa, $35 \%$ dariam remédio para dor na escola e $15 \%$ encaminhariam para o cirurgião-dentista. Na presente pesquisa, apenas $3,9 \%$ optaram por medicar o aluno na própria escola, no entanto, medicar requer o estabelecimento da patologia, conhecimento das indicações da medicação e histórico médico do paciente. Dessa forma, deve-se evitar fazê-lo por conta própria e procurar um profissional da área para essa finalidade.

Apesar do tema saúde bucal não ser abordado com frequência nas capacitações dos professores, 98,7\% deles acham importante ter orientações sobre medidas educativas e preventivas para a promoção da saúde bucal dos seus alunos. Campos et al. (2008) observaram que os conhecimentos dos professores sobre saúde bucal eram insatisfatórios, apesar disso, 91\% da amostra de seu estudo demonstrou vontade de participar de capacitação. Essa limitação de conhecimentos pode ser atribuída a condição de que os professores não recebem informações específicas e adequadas durante a formação acadêmica e continuada. Moura, Silva, Zermiani e Ditterich (2018) reforçam que os conhecimentos dos professores sobre saúde bucal, ainda, são muito limitados, possivelmente pela ausência de capacitações.

Vale ressaltar que $81,8 \%$ da amostra do presente estudo acharam importante que a educação em saúde seja realizada no ambiente escolar, destacando, também, que um pouco mais da metade dos professores $(50,6 \%)$ considerou que a tarefa de orientação sobre prevenção à cárie na fase escolar deveria ser uma ação conjunta entre professores, cirurgião-dentista e médico pediatra; $16,8 \%$ dos professores atribuíram essa responsabilidade, isoladamente, ao cirurgião-dentista e 1,2\% ao professor devidamente capacitado. Nenhum professor considerou que a escola não é local para essa atividade. Esses resultados destacam a aceitação da multidisciplinaridade no processo de educação em saúde bucal.

Dados similares foram encontrados por Rebello et al. (2018), que apontam a parceria entre professores, cirurgiãodentista e familiares $(80,7 \%)$ como responsável por esse processo trazendo a figura da família para partilhar a responsabilidade de orientação, uma vez que o que é aprendido na escola, deve ser sedimentado em casa. Deve-se, também, corresponsabilizar o sujeito envolvido na ação, neste caso, o aluno, para tanto, é fundamental que ele entenda o processo como a cárie ocorre e suas formas de prevenção, essa é uma das chaves para o sucesso de ações educativas em ambiente escolar.

No município pesquisado, o cirurgião-dentista da Estratégia de Saúde da Família (ESF), normalmente, é o responsável por essas atividades de promoção e prevenção de saúde bucal na escola, juntamente com o auxiliar de saúde bucal (ASB) e/ou agentes comunitários de saúde (ACS) e o faz, normalmente, com periodicidade trimestral ou quadrimestral. Sendo assim, é muito importante esse reconhecimento dos professores, que tem contato diário com os alunos, de sua importância como promotores de saúde no ambiente escolar. Em estudo recente, Cordeiro et al. (2019) observaram que 60,5\% dos professores acreditam que o conteúdo cárie e seus métodos de prevenção deveriam ser adotados no ensino fundamental. 
É importante que a escola trate assuntos que podem influenciar no pleno desenvolvimento escolar e na qualidade de vida dos alunos, uma vez que a dor de dente pode levar a ausências e faltas frequentes do aluno. Para tanto, faz-se necessária uma corresponsabilização social dos setores envolvidos, educação e saúde, como parte de uma formação ampla do indivíduo. Não se pode compreender ou transformar a situação de um indivíduo ou de uma comunidade sem levar em conta o enfrentamento de suas vulnerabilidades (Brasil, 1998; Brasil, 2013).

O nível de saúde bucal das pessoas reflete a maneira como vivem, numa interação entre hábitos individuais e condições de vida. Os professores relacionaram a percepção do estado de sua saúde bucal ao acesso aos serviços odontológicos. No presente estudo, $67,5 \%$ e 19,4\% dos professores classificaram a sua saúde bucal como boa e regular, respectivamente, e todos afirmaram tratar suas necessidades bucais com o cirurgião-dentista, já na amostra de Vellozzo et al. (2008) $47,5 \%$ dos professores classificaram a qualidade de sua saúde bucal como regular ou ruim, atribuindo isso à falta de acesso aos serviços odontológicos.

No presente estudo, verificou-se que $87 \%$ dos professores afirmaram já ter recebido algum tipo de orientação do seu cirurgião-dentista, dados em consonância aos encontrados por Pinheiro et al. (2005) em que $86 \%$ de professores de seu estudo receberam informações desses profissionais.

Vellozzo et al. (2008) verificaram que 71\% dos professores não achavam que seu atual estado de saúde bucal pudesse afetar a saúde de seus alunos, percentual um pouco menor que o encontrado na presente pesquisa, que apontou que $87 \%$ dos professores não achavam que seu estado de saúde bucal afeta a de seus alunos. Porém, vale ressaltar que, os padrões de comportamentos favoráveis ou desfavoráveis, são construídos desde a infância e as crianças tendem a imitar as pessoas que vêm (Aditista et al., 2020).

Os achados dessa pesquisa dão conta de que $64,9 \%$ dos professores não verificam o estado em que se encontra as escovas de dentes de seus alunos e que 76,6\% não fazem a troca das mesmas. Essa ocorrência pode ser pela razão de que $62,3 \%$ dos professores não costumam levar os alunos para escovar os dentes, portanto, não tem contato com as escovas de dentes. No instrumento da presente pesquisa não foi abordado os motivos pelos quais a escovação não era realizada. No estudo de Santos et al. (2015), todos os professores verificam o estado das escovas de dentes dos alunos e 92,8\% fazem a troca. Esse estudo foi realizado em uma creche, porém não explicitou a frequência da troca das escovas de dentes, nem em que essa troca se baseia, tampouco quem disponibiliza as escovas. Uma das funções das instituições de educação infantil, como primeiro espaço de educação coletiva das crianças fora do contexto familiar, é assistir as necessidades básicas de todas as crianças (Brasil, 2013).

No município pesquisado a Secretaria de Educação não disponibiliza escovas de dentes para os alunos, essa dispensação é realizada através da Secretaria de Saúde e acontece quando o cirurgião-dentista da ESF vai às escolas realizar ações de promoção e prevenção de saúde bucal. A escova é entregue ao aluno e pode ficar na escola ou ser levada para casa.

No aspecto durabilidade da escova os resultados obtidos nesta pesquisa estão expostos na Figura 5. 
Figura 5 - Frequência absoluta $(\mathrm{N})$ sobre o tempo de duração da escova de dentes dadas pelos professores de $1^{\circ}$ e $2^{\circ}$ ano de Escolas Municipais de Ensino de um município do interior de Alagoas que responderam.

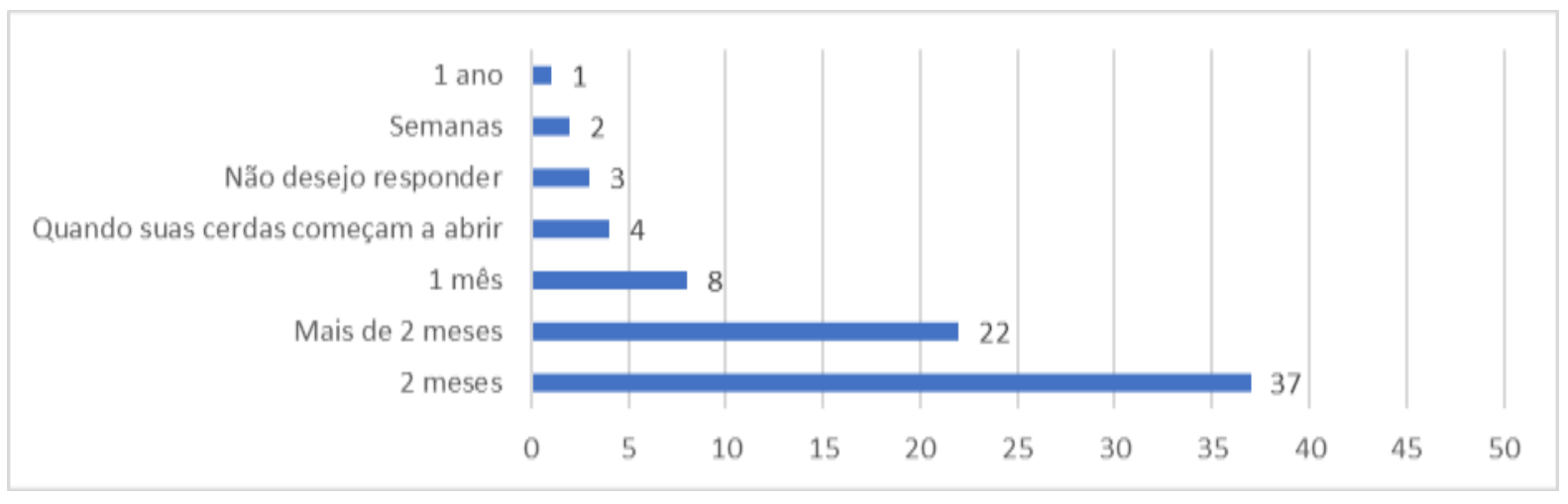

Fonte: Autores (2021).

Os resultados apresentados acima evidenciaram que os professores consideram o tempo de uso da escova como o fator mais importante para indicar a sua troca, uma vez que $48 \%$ dos professores escolheram a alternativa que indicava a substituição a cada dois (2) meses de uso, 28,5\% marcaram que a escova deveria ser substituída com mais de dois (2) meses de uso, $10,3 \%$ com 1 mês, 5,1\% trocariam a escova quando as cerdas começam a abrir, 3,8\% não responderam, 2,5\% disseram que a troca deveria acontecer em semanas e 1,2\% que essa troca seria 1 vez ao ano. Resultados em sintonia aos da pesquisa ora apresentada, em que 28,5\% dos professores acreditam que a durabilidade da escova é superior a 2 meses, foram encontrados por Santos et al. (2015), que também mostraram um percentual de 28,5\% mais de 2 meses. Em contrapartida apenas 5,2\% dos professores desse estudo entendem que a escova deva ser trocada quando suas cerdas começarem a abrir contra $14,2 \%$ do estudo de Santos et al. (2015). Coutinho et al., (2007) trazem que, independentemente do tempo de uso, o desgaste da escova diminui a eficiência de remoção da placa bacteriana ou biofilme, não devendo apenas o fator tempo ser observado para indicar a troca da escova dental, a condição da escova deve, também, indicar essa necessidade.

Um resultado que chama a atenção é que $62,3 \%$ dos professores do presente estudo não sabiam o que fazer diante de um acidente que atingisse a boca de seu aluno, corroborando com os achados por Pinheiro et al. (2005), em que 86\% dos professores também não sabem como proceder frente a um acidente bucal. Essa situação precisa ser repensada, uma vez que, muitos acidentes envolvendo a cavidade oral das crianças podem acontecer na escola e a conduta dos professores, nesse momento, pode ser decisiva para o sucesso do tratamento, como no caso de uma avulsão dentária.

Evidenciou-se neste estudo, o índice elevado de professores que não responderam a algumas questões, notadamente as questões abertas. Esse chegou a 57\%, ou seja, 44 sujeitos que não deram nenhum tipo de resposta, num total de 77 professores. Talvez esse fato se deva a dificuldade de organizar ideias sobre saúde bucal, uma vez que essa temática é pouco abordada nas capacitações dos docentes e seus conhecimentos parecem ser obtidos das orientações recebidas pelo cirurgião-dentista ou informações através de iniciativa própria, como colocado em algumas respostas fornecidas pelos professores, como internet, panfletos entre outros.

Observou-se, ainda, que quando as perguntas eram dicotômicas ou de múltipla escolha, para as quais os professorem tinham apenas que escolher uma das alternativas, as respostas variaram de totalmente respondidas a um percentual pequeno de questões não respondidas que chegou ao máximo de 14,2\% (11 professores). Já quando o discurso foi livre e se perguntou como e quais informações os professores possuíam sobre determinado assunto e quais seriam suas condutas frente a uma situação pré-estabelecida, obteve-se um número significativo de professores, entre 10 e 44 indivíduos, que optaram por não responder as questões. Notou-se, também, que quando as perguntas eram referentes sobre as informações que tinham, estas 
foram mais facilmente respondidas. Ao passo que sobre as condutas esperadas apresentaram um índice maior de não respondentes.

Nesse sentido, supõe-se que as perguntas poderiam não estar bem formuladas, além disso, como o formulário tinham 30 questões, sendo 10 abertas que exigiam escrita dos professores e levam mais tempo para serem respondidas, é possível que os participantes tenham ficado cansados ou talvez não tenham sentido motivação para responder àquela determinada questão específica ou, ainda que os professores tenham receio em apresentar o que conheciam sobre os assuntos abordados. Nesse sentido, pesquisas que possam fazer entrevistas com os professores podem ajudar na diminuição desses números.

Existe uma variedade de conteúdos nos instrumentos para a coleta de dados, para avaliar os conhecimentos dos professores, tais como: conhecimentos sobre cárie, doença periodontal, alimentação, escovação, fio dental, flúor, uso de mamadeira, uso de chupeta entre outros se esses conhecimentos eram aplicados em sala de aula e de que maneira. Sugere-se, a partir dessa multiplicidade de informações, a padronização de um instrumento para coleta de dados e que este não apresente questões abertas, em função da dificuldade encontrada para realizar a categorização das respostas e do possível cansaço que essas perguntas, quando frequentes, podem causar aos participantes.

Pode-se observar ainda, que apesar da maioria dos professores terem especialização, o que correspondeu a $74 \%$ da amostra, nas questões abertas, cuja escrita das respostas foi livre, as colocações feitas por eles, assim como no estudo de Unfer e Saliba (2000), apresentaram confusão de conceitos ou interpretação da pergunta, semelhante ao conhecimento empírico, apontando para pouco ou parcial domínio sobre o assunto.

\section{Conclusões}

Pelos dados analisados, conclui-se que os conhecimentos e as condutas apresentados pelos professores foram insuficientes e, muitas vezes, superficiais, pois partiram, predominantemente, da prática diária (conhecimento empírico) e não estiveram permeados, na maior parte das vezes, por informações técnicas suficientes. Sendo assim, para que os professores possam atuar como propagadores de conhecimento para a melhoria da saúde bucal de seus alunos, no ambiente escolar, necessitam de mais conhecimentos e informações, sendo necessário que os professores tenham conhecimento técnico específico de saúde bucal e utilizem metodologias adequadas à construção ou modificação do comportamento desejado. Dessa maneira, sugere-se, a inclusão de conteúdos específicos de saúde bucal nas capacitações e formação dos docentes, diminuindo, assim essa lacuna, uma vez que os professores se mostraram favoráveis a participar de capacitações e acharam importante a multidisciplinaridade. Assim como, que as políticas públicas de saúde bucal nas escolas estejam baseadas no planejamento de suas ações através de estratégias que partam de dados coletados sobre os conhecimentos e práticas dos docentes, e que essas ações possam ser avaliadas e tragam benefícios à comunidade escolar. Para estudos futuros a padronização de um instrumento para coleta de dados e que este não apresente questões abertas.

\section{Referências}

Aditista, R., Wafa, W., Riyanti, E., \& Setiawan, A. S. P. P. (2002). Effectiviness of educational vídeo in improving oral hygiene in preschool students. Padjadjaran Journal of Dentistry, 2(32), 108-112.

Alves, D. M., Santos, A. A., Santos, T. J., Bomfim, A. M. A., \& Calado, A. A. (2003). Avaliação da eficácia de uma escova e fita dentais alternativas utilizadas na higienização bucal em escolares da rede pública. Odontologia Clínico-Científica, 2(3), 191-195.

Antunes, L. S., Soraggi, M. B. S., Antunes, L. A. A., \& Corvino, M. P. F. (2006). Avaliação da percepção das crianças e conhecimentos dos educadores frente à saúde bucal, dieta e higiene. Pesquisa Brasileira em Odontopediatria e Clínica Integrada, 6(1), 79-85.

Arcieri, R. M., Rovida, T. A. S., Lima, D. P., Garbin, A. J. I., \& Garbin, C. A. S. (2013). Análise do conhecimento de professores de Educação Infantil. Educar em Revista, 29(47), 301-314. 
Research, Society and Development, v. 10, n. 17, e191101724384, 2021 (CC BY 4.0) | ISSN 2525-3409 | DOI: http://dx.doi.org/10.33448/rsd-v10i17.24384

Associação Brasileira de Odontopediatria Nacional. (2020). Diretrizes para procedimentos clínicos em odontopediatria (3a ed). Editora Santos.

Brasil. Ministério da Educação e Cultura. Secretaria de Educação Fundamental (1998). Parâmetros Curriculares Nacionais: terceiro e quarto ciclos: apresentação dos temas transversais. Brasília.

Brasil. Ministério da Educação. Secretaria de Educação Básica. Secretaria de Educação Continuada, Alfabetização, Diversidade e Inclusão. Conselho Nacional de Educação (2013). Diretrizes Curriculares Nacionais da Educação Básica. Brasília.

Campos, L., Bottan, E. R., Farias, J., \& Silveira, E. G. (2008). Conhecimento e atitudes sobre higiene bucal dos professores do ensino fundamental de Itapema - SC. Revista de Odontologia da UNESP, 37(4), 389-394.

Carvalho, P. H. A., Ludtke, S. T., Ferreira, M., Leite, F. R. M., Lund, R. G., \& Schardosim, L. R. (2016). Avaliação de uma proposta educativa em saúde bucal aplicada ao ensino básico, Odontol. Clín.-Cient, 15(1), 31-38.

Cordeiro, G. A., Silva, M. F., Daroz, L. G. D., \& Daroz, C. B. S. (2019). Conhecimento sobre cárie dentária entre docentes do ensino médio. Revista ABENO, 19(3), 133-143.

Costa, M. M., Barbosa, A. D. L., Fernandes, J. M. F. A., Fonseca, F. R. A., \& Paredes, S. O. (2014). Conhecimento e práticas em saúde bucal nas escolas de ensino fundamental de um município de pequeno porte do sertão paraibano. Arquivos em Odontologia, 50(4), $193-202$.

Coutinho, P. G., Bittar, P., Ditterich, R. G., Santos, F. A., \& Wambier, D. S. (2007). Avaliação do índice de desgaste de escovas dentais utilizadas por préescolares. Revista de Odontologia da UNESP, 36(1), 97-101.

Garbin, C. A. S., Rovida, T. A. S., Garbin, A. J. I., Arcieri, R. M., Souza, N. P., \& Moimaz, S. A. S. (2012). Saúde bucal e educação infantil: avaliação do desgaste e do acondicionamento de escovas dentárias utilizadas por pré-escolares. Revista de Odontologia da UNESP, 41(2), 81-87.

Garbin, C. A. S., Rovida, T. A. S., Peruchini, L. F. D., \& Martins, R. J. (2013). Conhecimento sobre saúde bucal e práticas desenvolvidas por professores do ensino fundamental e médio. RFO, 18(3), 321-327.

Grancille Garcia, A. F., Silva, J. M., Guinho, S. F., \& Menezes, V. (2007). Conhecimento de professores do ensino fundamental sobre saúde bucal. RGO, $55(1), 29-34$

Lemkuhl, I., Souza, M. V. C., Cascaes, A. M. \& Bastos, J. L. (2015). A efetividade das interações educativas em saúde bucal: revisão de literatura. Caderno de Saúde Coletiva, 23(3), 336-346.

Moura, A. M. G., Silva, R. O. C., Zermiani, T. C., \& Ditterich, R. G. (2018). Conhecimento sobre saúde bucal de professores de escolas públicas em Colombo-PR. Revista Espaço para a Saúde, 19(1), 57-64.

Pinheiro, H. H. C., Cardoso, D. G., Araújo, M. V. A., \& Araújo, I. C. (2005). Avaliação do nível de conhecimento sobre saúde bucal dos professores da Creche Sorena, Belém, Pará. Revista do Instituto de Ciências da Saúde, 23(4), 297-303.

Rebello, M. G., Oliveira, C. M. L., Nogueira, A. J. S., Corrêa, B. D., \& Rebello, F. K. (2018). Percepção de professores paraenses sobre saúde bucal infantil. HOLOS, 5, 216-230.

Sá, L. O., \& Vasconcelos, M. M. V. B. (2009). A importância da educação em saúde bucal nas escolas de ensino fundamental - Revisão de literatura. Odontologia Clínico-Científica, 8(4), 299-303.

Santos, P. A., Rodrigues, J. A., \& Garcia, P. P. N. S. (2003). Conhecimento sobre prevenção de cárie e doença periodontal e comportamento de higiene bucal de professores de ensino fundamental. Ciência Odontológica Brasileira, 6(1), 67-74.

Santos, M. O., Casotti, C. A., Guimarães e Queiroz, A. P. D., Carneiro, J. A. O., \& Uemura, T. F. (2015). Conhecimento e percepção sobre saúde bucal de professores e pré-escolares de um município baiano. RFO UPF, 20(2), 172-178.

Santos, A. A., Alves, C. F., Warren, E. M. C., \& Wyszomirska, R. M. A. F. (2019). Integrated Modal of Course Based on Edu-Communication and PsychoCommunication in Learning. Creative Education, 10(6), 1080-1090. https://file.scirp.org/pdf/CE_2019061115430264.pdf.

Silva, R. A., Nóia, N. B., Gonçalves, L. M., Pinho, J. R. O., \& Cruz, M. C. F. M. (2013). Avaliação da participação de mães em um programa de prevenção e controle de cáries e doenças periodontais para lactentes. Revista Paulista de Pediatria, 31(1), 83-89.

Silva, C. V. (2015). Avaliação do conhecimento dos professores do ensino fundamental da rede pública de Ouro Preto do Oeste - RO sobre saúde bucal. Ciência Odontológica Brasileira, 23(45/46), 1-10.

Toassi, R. F. C. \& Petry, P. C. (2021). Metodologia científica aplicada à área da Saúde. Editora da UFRGS.

Unfer, S., \& Saliba, O. (2000). Avaliação do conhecimento popular e práticas cotidianas em saúde bucal. Revista de Saúde Pública, $34(2)$, 190-195.

Vazzoler, L. O., \& Cericato, G. O. (2016). Condições de saúde bucal em escolares de um município do interior do Rio Grande do Sul. Journal of Oral Investigations, 5(2), 23-26.

Vellozo, R. C. A. D. M., Queluz, D. P., Mialhe, F. L., \& Pereira, A. C. (2008). Avaliação dos conhecimentos e práticas em saúde bucal de profissionais do ensino fundamental. Pesquisa Brasileira em Odontopediatria e Clínica Integrada, 8(2), 153-158. 